\title{
OPTIMUM LOCATION OF PSS AND ITS PARAMETERS BY USING PARTICLE SWARM OPTIMIZATION
}

\author{
Avdhesh Sharma \\ Professor, EE Department, MBM Engineering College, Jodhpur, Rajasthan India. \\ Rajesh Kumar \\ Research Scholar, EE Department, MBM Engineering College, Jodhpur, Rajasthan India.
}

\begin{abstract}
This paper deals with stability of interconnected power system using optimum power system stabilizer (PSS) present at generators. Tuning of PSS parameters has been done using particle swarm optimization (PSO) algorithm. This can be achieved by the modal analysis of IEEE 10 machine 39 bus New England system in Matlab-Simulink. A comparative analysis of IEEE 10 machine 39 bus system has been carried out for investigating the effectiveness of PSS at all generators and with PSS only at generators which were having modal analysis based higher participation factor. Tuning of PSS is an important issue in wide area control system, hence we can tune only the PSS at optimal locations of generators and tuning time got decreased however system was still stable. Investigation shows that the optimum PSS increases the damping of the electromechanical modes and stabilizes the entire system disturbance.
\end{abstract}

Key words: Power System Stabilizer (PSS), Particle Swarm Optimization (PSO), HBMO, GA, Generator model, Excitation system Model, Participation Factor, Delta Omega PSS.

Cite this Article: Avdhesh Sharma, Rajesh Kumar, Optimum Location of PSS and its Parameters by Using Particle Swarm Optimization, International Journal of Advanced Research in Engineering and Technology, 10 (2), 2019, pp 571-584.

$\mathrm{http} / / /$ iaeme.com/Home/issue/IJARET?Volume=10\&Issue $=2$

\section{INTRODUCTION}

The essential expectation of including a power system stabilizer (PSS) is to improve damping to broaden the control limits. The idea of PSS limits its viability to day-to-day outages about a consistent operating point. The outages around an operating point are ordinarily the after effect of an electrical framework that is damped in a refine manner which can cause unconstrained developing motions or system modes of oscillations [4]. This paper presents the most essential part of various information signals utilized as useful control signals to power system stabilizer (PSS) for damping of power system oscillations. The impact of PSS in the power system on its viability in damping out system oscillations has been dissected. Diverse control systems were utilized to evaluate the most fitting optimal location of the PSS for accomplishing great 
damping of electromechanical motions. The investigation in this paper is done on a 10 machine 39 bus Simulink model under various working conditions. Poor or even negative damping of machine swing modes can undoubtedly happen in far-reaching interconnected power system with critical power exchange crosswise over long distances.

A lot of research has been presented in the literature on particle swarm optimization (PSO) algorithm for various optimization works. The optimal power flow (OPF) and optimal design of PSS [18] \& [19] which describes the fuel cost minimization, voltage stability and voltage profile improvement. Researchers had suggested various optimization problem on a multimachine system for the optimal locations of PSS [8],[11]-[13]. The tuning of PSS by using Honey BEE Mating Optimization (HBMO) was presented in [9]. Also [15] \& [16] suggested a method to design a PSS using simplified version of Genetic Algorithm (GA). The description of inter-area modes of oscillation has been compared using a New PSS design in [16]. A conventional approach for the design of PSS in multimachine system has been described and implemented with the help of PID Controller [17].

With the latest technology on digital platform, software based digital automatic voltage regulators have been used with properly tuned PSS parameters in order to accomplish proper excitation system. The performance of excitation system can also be improved from critical conditions [5]-[6]. Although a lot of research work has been reported in the literature on PSS, even than a sincere effort has been made to tune PSS parameters using PSO technique. In this paper the topics covered are as follows:

- To study the responses of New England (10 machine 39 bus system) with and without PSS.

- Determine the optimum location of PSS in multimachine system and study the behavior of system with and without PSS.

- Tuning of PSS parameters by using Particle swarm algorithm (PSO).

\section{SYSTEM INVESTIGATED}

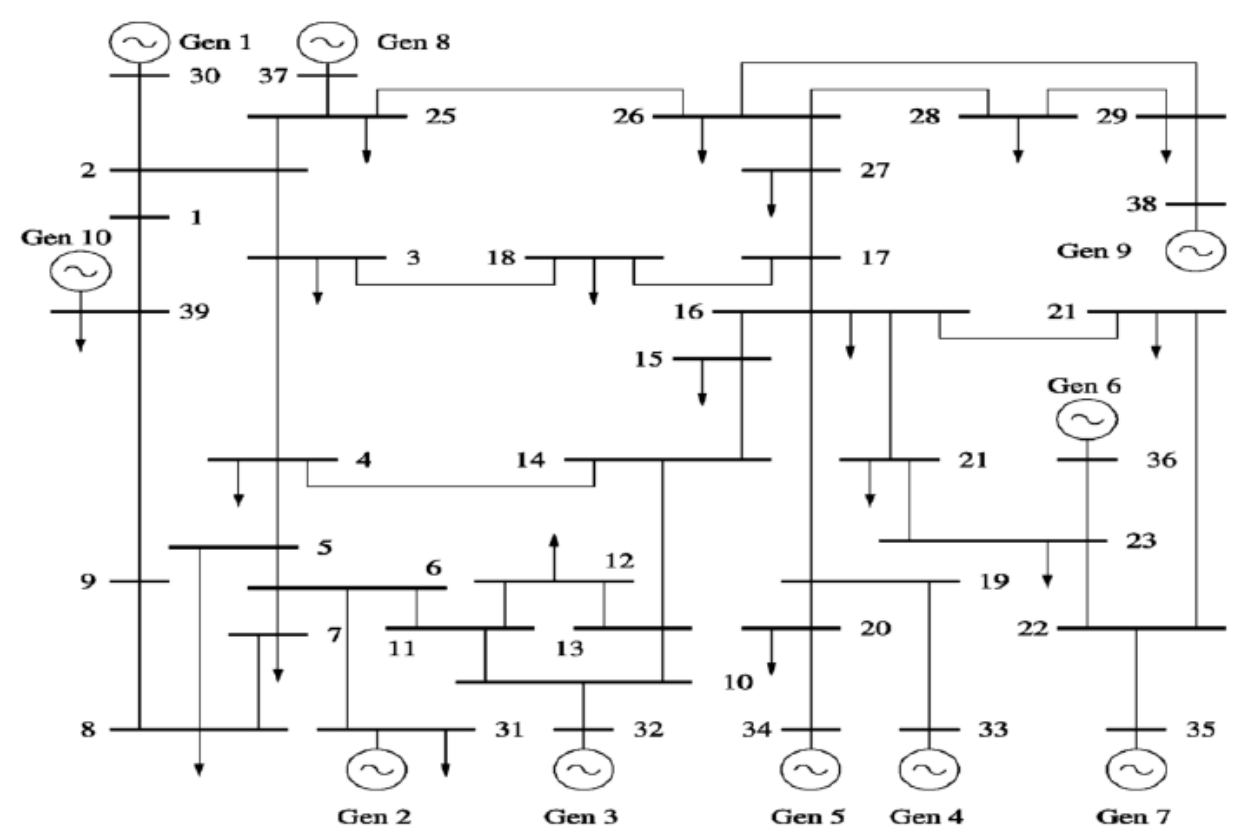

Figure 1 Single line diagram of a 10 machine 39 bus New England System

IEEE 10 machine 39 bus New England system is considered for our analysis as shown in figure 1. The standard data of IEEE 10 machine 39 bus system is taken for our consideration [20]. IEEE type ST1A modal of static excitation system has been considered for all generators. 


\section{SYSTEM MODELLING}

\subsection{Dynamic Model}

The modeling of synchronous machine is done using simplified machine equations in state space form. For the analysis purpose the equivalent model of synchronous machine is considered and referenced to rotor reference frame (d-q frame) [7]. The dynamic model of the system investigated, is as follows.

$$
\begin{gathered}
\dot{\delta}_{l}=\omega_{b}\left(\omega_{i}-1\right) \\
\dot{\omega}_{l}=\frac{\left(T_{m i}-T_{e i}\right)}{2 H_{i}} \\
\dot{E}_{q l}=\frac{\left(E_{f d i}-\left(x_{d i}-\dot{x}_{d l}\right) i_{d i}\right)-E_{q i}}{T_{d o}} \\
\dot{E}_{f d l}=\frac{K_{A i}\left(V_{r e f i}-V_{t i}+U_{i}\right)-E_{f d i}}{T_{A i}} \\
T_{e i}=E_{d i} i_{d i}+E_{q i} i_{q i}
\end{gathered}
$$

Where suffix ' $\mathrm{i}$ ' represents the $\mathrm{i}^{\text {th }}$ generator bus $(\mathrm{i}=1, \ldots \ldots 10)$. It may be noted that the dynamic model is non-linear.

\subsection{Excitation System Model}

The static exciter model is considered on all the machines. Here the first block represents the Amplifier (i.e. Gain setting $K_{a}$ and time constant $T_{a}$ ). The output of the exciter is limited by saturation or power supply limitations. These limits may be represented by $\mathrm{V}_{\mathrm{rmax}}$ or $\mathrm{V}_{\mathrm{rmin}}$ as shown in figure 2. The second block is a Transient Gain Reduction (TGR) block. A commonly industry practice is to reduce the gain of the exciter at high frequencies by the use of TGR.

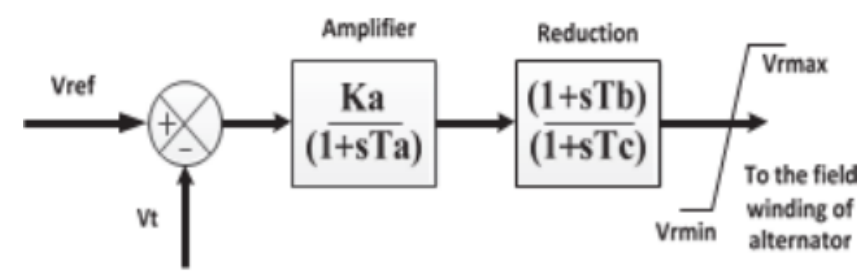

Figure 2 Excitation system Model

The value of the $\mathrm{K}_{\mathrm{a}} \& \mathrm{~T}_{\mathrm{a}}$ is taken as 50 and $0.001 \mathrm{sec}$ respectively for all the machines. $\mathrm{T}_{\mathrm{b}}$ and $\mathrm{T}_{\mathrm{c}}$ of the transient gain reduction block are taken as $1 \& 10$ respectively [19] \& [16]. This is common values for the AVR of all the machines [10].

\subsection{Delta-Omega PSS Model}

The Delta - Omega Power System Stabilizer (PSS) block can be used to add damping to the rotor oscillations of the synchronous machine by controlling its excitation. The disturbances occurring in a power system induces electromechanical oscillations in the electrical generators. These oscillations, also called power swings, must be effectively damped to maintain the system stability [3]. The output signal of the PSS is used as an additional input $\left(\mathrm{V}_{\text {stab }}\right)$ to the Excitation System block. The PSS input signal can either be the machine speed deviation, 'dw' or its 
accelerating power, $\mathrm{P}_{\mathrm{a}}=\mathrm{P}_{\mathrm{m}}-\mathrm{P}_{\mathrm{e}}$ (difference between the mechanical power and the electrical power).

The Delta-Omega Power System Stabilizer is modeled by the following nonlinear system.

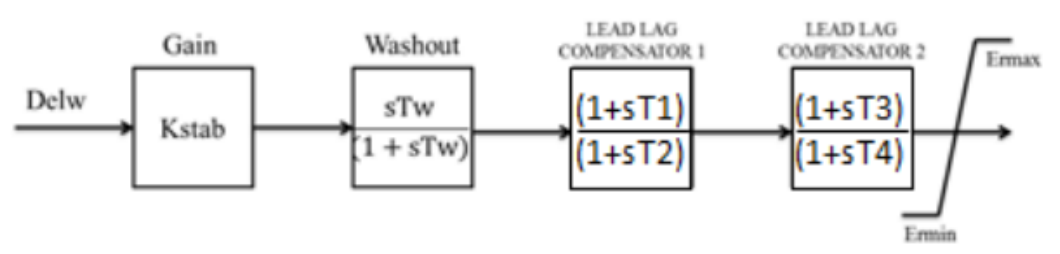

Figure 3 Delta Omega PSS Block Diagram [7]

In Fig-3, the model is used as a stabilizer for controlling the rotor oscillations, noise, speed deviation and the torsional modes. There are two types of stabilizers

- Direct measurement of shaft speed.

- Power Based Stabilizers

Out of the two, the direct measurement of shaft speed causes many adherent effects, like these filters are not sophisticated for the removal of lower frequency noise without the changes in the electro-mechanical components which are supposed to be measured. Here the above block diagram represents the Delta Omega PSS which is specifically designed for providing the sufficient damping to generator rotor oscillations with the control of its excitation using auxiliary control signal. Here washout block serves as a high pass filter, having the time constant ' $\mathrm{T}_{\mathrm{w}}$ ' which is high enough for passing the higher order signals without attenuation. For the industrial purposes the dynamic compensator block uses two lead-lag compensator blocks for limiting the maximum amount of damping. The time constant from T1 to T4 are set as per the range of frequency we desire and the amount of input signal needed. [7]

Power system stabilizers based on shaft speed deviation are known as Delta Omega $(\Delta \omega)$ stabilizers. Among the important considerations in the design of equipment for the measurement of generator, speed deviation is the minimization of noise due to shaft run-out and other causes. The allowable level of noise is dependent on its frequency.

For noise frequencies below $5 \mathrm{~Hz}$, the level must be less than $0.02 \%$, since significant changes in the terminal voltage can be produced by low frequency changes in the field voltage. Such a low frequency noise cannot be removed by conventional electric filters, its elimination must be inherent to the method of measuring the speed signal [14].

The participation factor indicates the PSS location to get the sufficient damping to damp out power system oscillations. It also indicates the states which participate more. So, this information will be useful to find out the locations where the PSS can be fixed. [1]

Although now-a days, PSS are coming in-built in synchronous generators with generator ratings above $70 \mathrm{MVA}$, all the generator are having ratings above $100 \mathrm{MVA}$ in 10 machine 39 bus New England power system [2]. So, we place PSS on all generator excitations system. PSS considered in this model is a speed deviation input PSS. The general block diagram for the PSS is shown in the figure 3. The same PSS is considered on all machines. The parameters of the

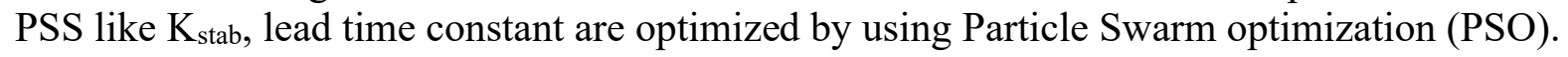

\section{OPTIMUM PSS PLACEMENTS IN A MULTIMACHINE SYSTEM}

For the determination and analysis of 10 machine 39 bus new England system, there is a need to determine the optimum locations of generators where PSS can be installed. There are many methods available for the determination of optimum location of PSS, here Participation Factor based technique is used and examined. [5] 
Table 1 Oscillatory Electromechanical Modes of The System Without PSS.

\begin{tabular}{|c|c|c|}
\hline Eigenvalue & $\begin{array}{c}\text { Natural } \\
\text { Frequency in Hz }\end{array}$ & $\begin{array}{c}\text { Damping } \\
\text { Ratio }\end{array}$ \\
\hline$-0.4043 \pm 9.484 \mathrm{i}$ & 1.5104 & 0.0426 \\
\hline$-0.4827 \pm 9.503 \mathrm{i}$ & 1.5152 & 0.0507 \\
\hline$-0.5013 \pm 9.231 \mathrm{i}$ & 1.4706 & 0.0542 \\
\hline$-0.3125 \pm 8.912 \mathrm{i}$ & 1.4197 & 0.0350 \\
\hline$-0.185 \pm 8.0097 \mathrm{i}$ & 1.2748 & 0.0231 \\
\hline$-0.2032 \pm 7.253 \mathrm{i}$ & 1.1555 & 0.0280 \\
\hline $\mathbf{0 . 3 4 9 4} \pm \mathbf{6 . 3 3 4 4 i}$ & $\mathbf{1 . 0 0 9 0}$ & $\mathbf{- 0 . 0 5 5 1}$ \\
\hline $0.0716 \pm 6.5139 \mathrm{i}$ & 1.0361 & -0.0110 \\
\hline$-0.0011 \pm 4.026 \mathrm{i}$ & 0.6414 & 0.0003 \\
\hline
\end{tabular}

Table 2 Participation Factors For $0.3494 \pm 6.3344 \mathrm{i}$

\begin{tabular}{|c|c|}
\hline $\begin{array}{c}\text { Associated State } \\
\text { Variable }\end{array}$ & $\begin{array}{c}\text { Magnitude of the } \\
\text { normalized } \\
\text { Participation Factors }\end{array}$ \\
\hline$\Delta \delta_{3}$ & 0.1017 \\
\hline$\Delta \omega_{3}$ & 0.1017 \\
\hline$\Delta \delta_{5}$ & 0.4543 \\
\hline$\Delta \omega_{5}$ & 0.4543 \\
\hline$\Delta \delta_{9}$ & 1.0000 \\
\hline$\Delta \omega_{9}$ & 1.0000 \\
\hline$\Delta \mathrm{E}_{99}$ & 0.2225 \\
\hline
\end{tabular}

Table 1 shows oscillatory electromechanical modes of the system without PSS where $0.3494 \pm 6.3344 \mathrm{i}$ is having the highest positive eigen value out of all the other eigen values. Each electromechanical modes of oscillations shown in Table 1 have the magnitude of the normalized participation factors corresponding to oscillatory mode. The magnitude of the normalized participation factor for a eigen value is associated with speed variables of each generator. Table 2 shows only those participation factors whose normalized magnitude is greater than 0.1 corresponding to the oscillatory mode $0.3494 \pm 6.3344 \mathrm{i}$. Examination of this table clearly shows that optimum location of PSS is at machine no 9, 5 and 3 and the maximum participation is of machine number 9 [16].

Following the above approach optimum locations of the PSS for enhancing damping of other modes have been obtained (Table 3).

Table 3 Weakly Damped Modes Optimum PSS Locations [16]

\begin{tabular}{|c|c|}
\hline $\begin{array}{c}\text { Weakly damped oscillatory } \\
\text { mode }\end{array}$ & $\begin{array}{c}\text { Optimum PSS location } \\
\text { (Generator } \\
\text { number) }\end{array}$ \\
\hline$-0.4043 \pm 9.484 \mathrm{i}$ & 8 \\
\hline$-0.4827 \pm 9.503 \mathrm{i}$ & 7 \\
\hline$-0.5013 \pm 9.231 \mathrm{i}$ & 5 \\
\hline$-0.3125 \pm 8.912 \mathrm{i}$ & 2 \\
\hline$-0.185 \pm 8.0097 \mathrm{i}$ & 1 \\
\hline$-0.2032 \pm 7.253 \mathrm{i}$ & 5 \\
\hline $0.3494 \pm 6.3344 \mathrm{i}$ & 9 \\
\hline $0.0716 \pm 6.5139 \mathrm{i}$ & 5 \\
\hline$-0.0011 \pm 4.026 \mathrm{i}$ & 7 \\
\hline
\end{tabular}

Identification of locations of PSS for enhancing damping of a particular mode is necessary in order to arrive at optimum parameters of the PSS.

By the above discussion, it is concluded that the generators number 9,5 and 3 in 10 machine 39 bus system have the maximum participation among all the other generators. Hence if the PSS of these generators are tuned properly then there is no need for tuning the parameters of other PSS in wide area control system. 


\section{DESIGN OF CONVENTIONAL PSS USING PSO}

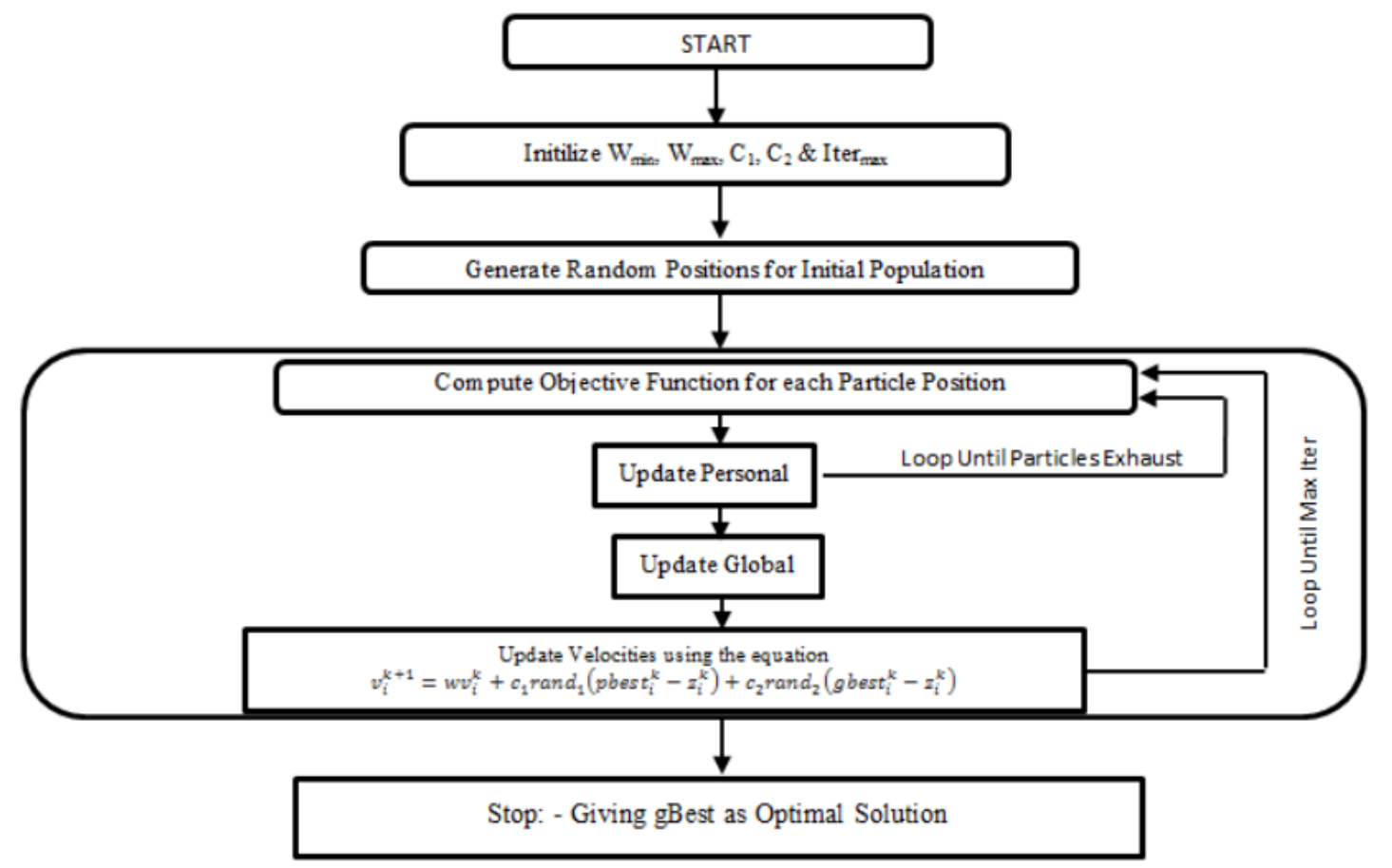

Figure 4 Flowchart of the Particle Swam Optimization Technique

In order to increase the damping of the rotor oscillations, a PSS utilizing shaft speed deviation is used as input signal. Figure 3 shows the transfer function block diagram of a conventional Power system stabilizer ( $i^{\text {th }}$ machine), where ' $i$ ' is machine number and varies from 1 to 10 .

To optimise PSS parameters, the PSO algorithm implementation process has been presented here and explained by using a flow chart as shown in Figure 4.

The optimum parameter values of the PSS have been obtained by minimizing the popular integral of time multiplied by sum of square value of the error (ITSE), which is given by.

$$
J=\operatorname{Min} \int_{0}^{t}\left(t * \sum_{i=1}^{n}(e(t))^{\wedge} 2\right) \mathrm{dt}
$$

Here error $\mathrm{e}(\mathrm{t})=\Delta \mathrm{w}$ which is speed deviation of synchronous machine.

and ' $n$ ' is the number of synchronous machine $(1,2 \ldots \ldots$ 10). In our case, there are 10 synchronous machines. So, the objective function becomes as follows: [19]

$\sum_{i=1}^{n}(e(t))^{\wedge} 2=\Delta \mathrm{w}_{1}{ }^{2}+\Delta \mathrm{w}_{2}{ }^{2}+\Delta \mathrm{w}_{3}{ }^{2}+\Delta \mathrm{w}_{4}{ }^{2}+\Delta \mathrm{w}_{5}{ }^{2}+\Delta \mathrm{w}_{6}{ }^{2}+\Delta \mathrm{w}_{7}{ }^{2}+\Delta \mathrm{w}_{8}{ }^{2}+\Delta \mathrm{w}_{9}{ }^{2}+\Delta \mathrm{w}_{10}{ }^{2}$

During optimization the following parameters are considered.

For tuning process, a mechanical power input of the machine number 8 is changed from 0.54 to $(0.54+(1 \%$ of 0.54$))$. Then as described above using PSO and taking all the machine error simultaneously and optimizing two parameters of the PSS, mainly the $\mathrm{K}_{\text {stab }}$ and the lead time constant keeping lag time constant fixed.

The two lag time constants are kept fixed at $\mathrm{T} 2=\mathrm{T} 4=0.05$. Here we also assumed that the two lead time constants are same. So we have two parameters to be optimized for three machines G9, G5 and G3. One is $\mathrm{K}_{\text {stab }}$ and other is lead time constant, T1 \& T3 keeping T2 \& T4 to be same. Taking the three machine parameters simultaneously so total number of parameters to be optimized becomes 6 . The typical values of the optimized PSS parameters are considered which lie between [0.001-50] for $\mathrm{K}_{\text {stab, }}[0.06-1.0]$ for $\mathrm{T}_{1}$ and $\mathrm{T}_{3}$. 
Table 4 Optimized PSS Parameters

\begin{tabular}{|c|c|c|c|c|c|}
\hline Machine No. & Kstab & T1 & T2 & T3 & T4 \\
\hline 3 & 32 & 0.8 & 0.05 & 0.8 & 0.05 \\
\hline 5 & 28 & 0.9 & 0.05 & 0.9 & 0.05 \\
\hline 9 & 34 & 0.7 & 0.05 & 0.7 & 0.05 \\
\hline
\end{tabular}

\section{ANALYSIS}

In this section, analysis of the system dynamic responses with PSS and without PSS has been carried out.

\subsection{Initial Loading Data for all Generators}

Initial loading of the generators for the 10 machine 39 bus system were obtained using MATLAB Simulink software package by executing load flow program for getting initial system loading and generation. Table 5 shows the Generator ratings $\left(P_{n}, V_{n}\right)$, generator input and outputs powers $\left(\mathrm{P}_{\mathrm{n}}, \mathrm{P}_{\mathrm{e}}\right)$ and field voltage $\left(\mathrm{V}_{\mathrm{f}}\right)$ in pu of all 10 machines.

Where, $\mathrm{P}_{\mathrm{n}}=$ Nominal rating of synchronous generator in MVA

$\mathrm{V}_{\mathrm{n}}=$ Nominal rating of synchronous generator in $\mathrm{KV}$

$\mathrm{P}_{\mathrm{e}}=$ Electrical power out on its own machine base in MWs

$\mathrm{P}_{\text {mech }}=$ Mechanical power input in $\mathrm{MW}$

$\mathrm{Vf}=$ Field voltage in $\mathrm{pu}$

Table 5 Generators rating, input and output power and field voltages.

\begin{tabular}{|c|c|c|c|c|c|}
\hline S No. & $\begin{array}{c}\text { Pn } \\
\text { (MVA) }\end{array}$ & $\begin{array}{c}\text { Vn } \\
\text { (KV) }\end{array}$ & $\begin{array}{c}\text { Pe } \\
\text { (MW) }\end{array}$ & $\begin{array}{l}\text { Pmech } \\
\text { (MW) }\end{array}$ & Vf (pu) \\
\hline G1 & 1000 & 20 & 1000 & 1000 & 1.033 \\
\hline G2 & 900 & 20 & 447 & 447 & 2.3029 \\
\hline G3 & 900 & 20 & 650 & 650 & 2.051 \\
\hline G4 & 900 & 20 & 632 & 632 & 2.055 \\
\hline G5 & 900 & 20 & 508 & 508 & 3.7433 \\
\hline G6 & 900 & 20 & 650 & 650 & 2.7162 \\
\hline G7 & 900 & 20 & 560 & 560 & 1.6983 \\
\hline G8 & 1000 & 20 & 540 & 540 & 1.8387 \\
\hline G9 & 1000 & 20 & 830 & 830 & 1.9529 \\
\hline G10 & 900 & 20 & 250 & 250 & 0.9966 \\
\hline
\end{tabular}

\subsection{Dynamic Response of System without PSS and with PSS at all 10 Generators.}

To examine the effectiveness of PSS, dynamic responses of all generators with and without PSS were obtained using simulink modal by considering $1 \%$ step disturbance in mechanical power at $1 \mathrm{sec}$ on G8. Here PSS parameters are $\mathrm{Kstab}=35, \mathrm{~T} 1=\mathrm{T} 2=0.1 \mathrm{sec}$ and $\mathrm{T} 3=\mathrm{T} 4=0.05 \mathrm{sec}$ and same parameters are considered for all other generators. 

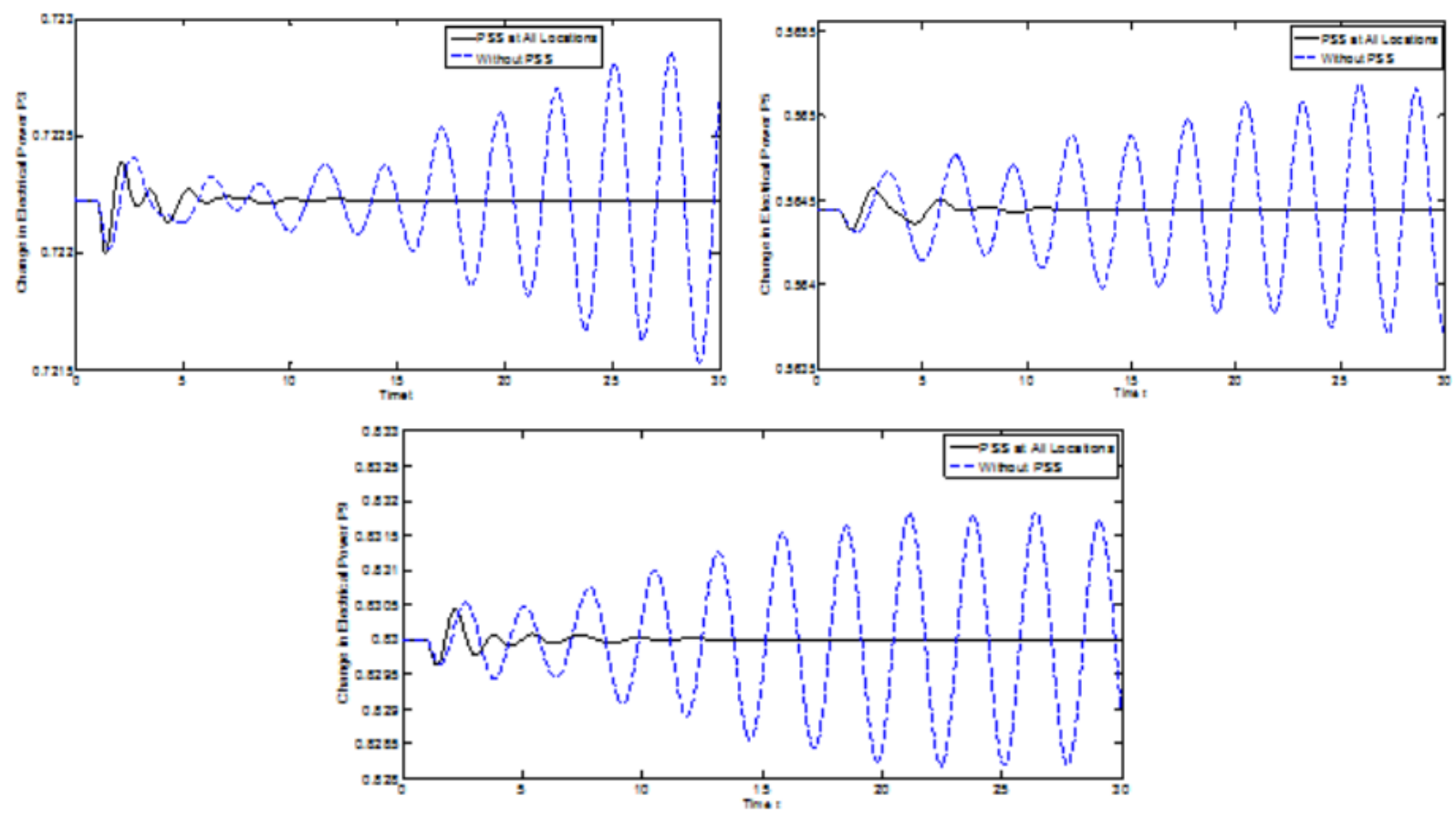

Figure 5 Change in Electrical power output of generators (a) G3, (b) G5 and (c) G9.

For comparative study point of view, power output of only three generators (optimal locations G3, G5 and G9) are shown in figure 5. Examining the responses shown in figure 5, it clearly indicates that due to the application of PSS, an unstable system becomes stable and electrical power output stabilizes within 14 seconds.

Here we have shown the results of only three machines or generators because of the reason that these are the only machines which have the maximum participation in dynamic response of IEEE 10 Machine 39 Bus New England System.

Dynamic responses of the system with and without PSS for speed deviation and change in the terminal voltages were also obtained and are also shown in figure no $6 \& 7$ respectively. It can be observed from the figures that without PSS, responses are oscillatory with increasing amplitudes (Unstable), whereas with PSS, the responses are slightly oscillatory and quickly damp out (stable). Here the dynamic response of the system with PSS stabilizes the speed deviation within 10 seconds whereas change in terminal voltage stabilizes in 8 seconds.
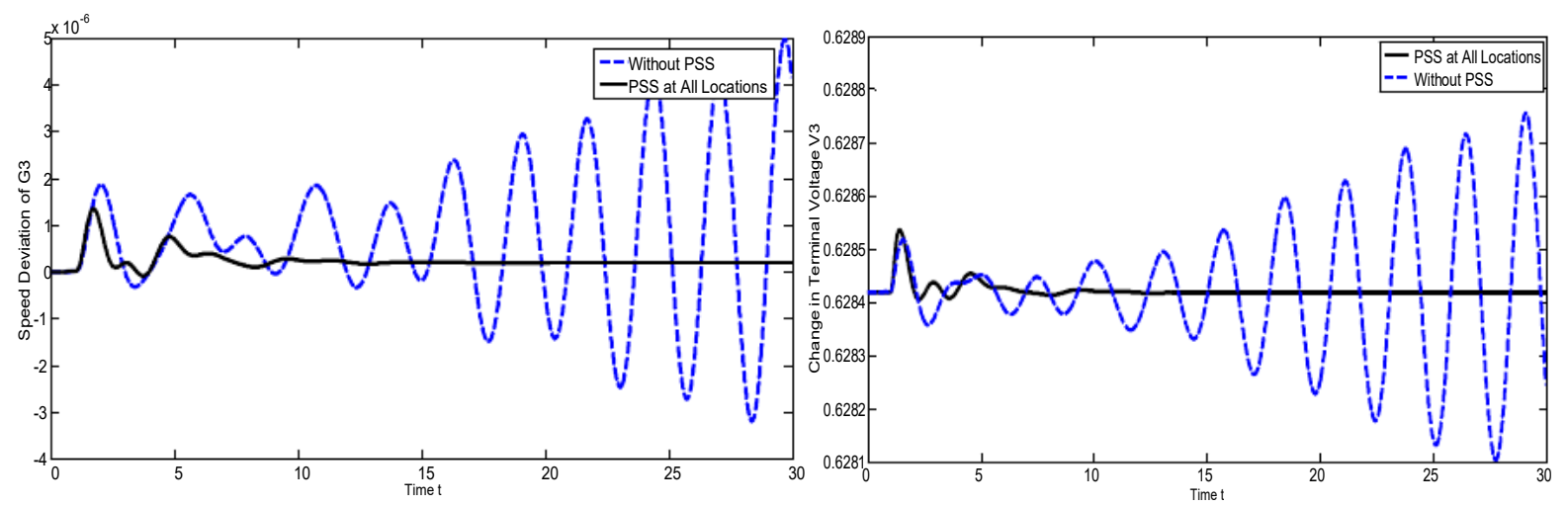

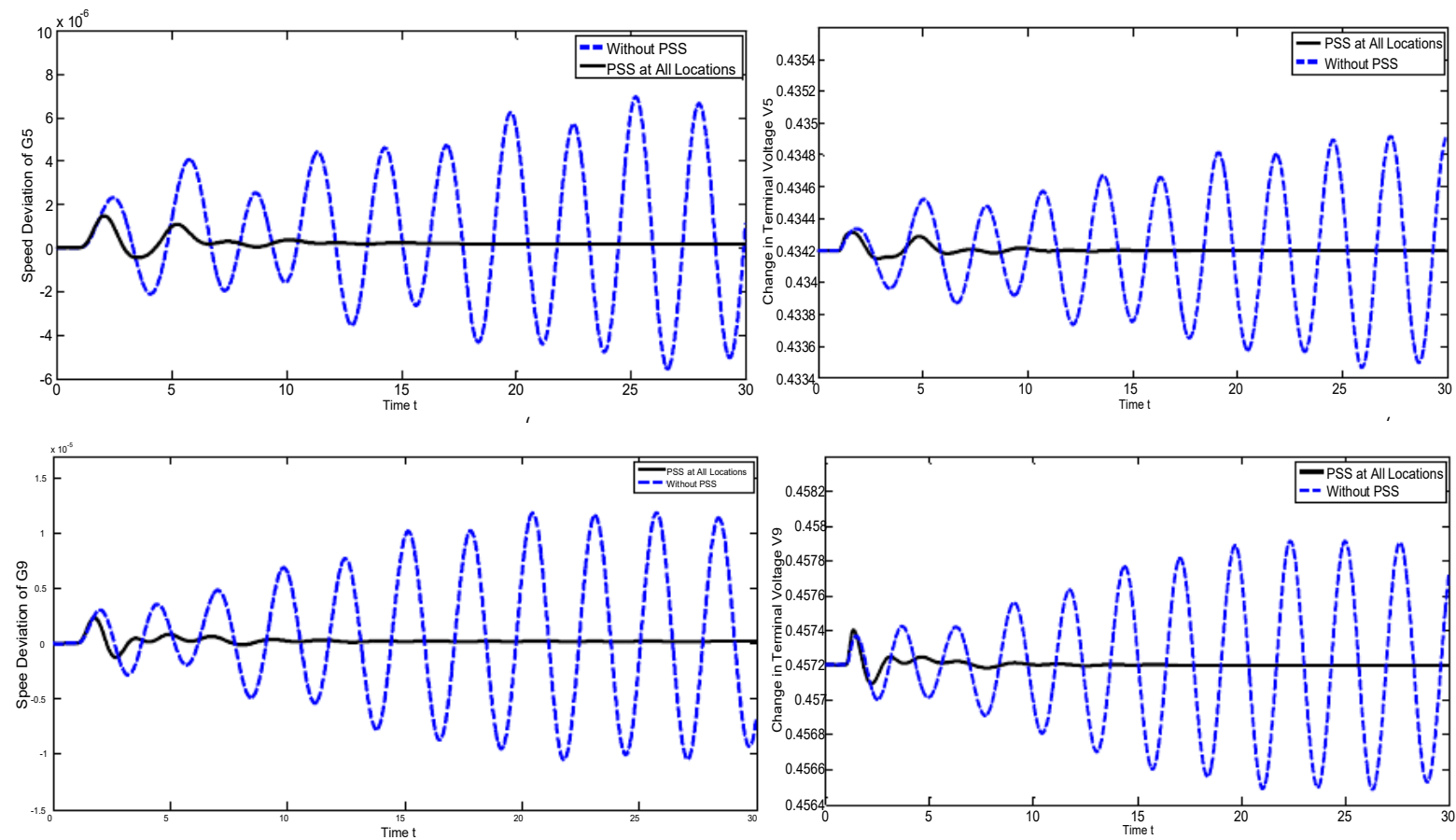

Figure 6 Speed deviation of (a) G3, (b) G5 and (c) G9 (a) G3, (b) G5 and (c) G9

Figure 7 Change in Terminal Voltages of

\subsection{Study the sensitivity of PSS Gain of installed PSS at optimal Locations (G3, G5, G9)}

To examine the sensitivity of the PSS gain, system dynamic response was obtained for change in the electrical power output of all generators by considering $1 \%$ step change in mechanical power output of G8. Here gain of the PSS installed at G3, G5 and G9 were reduced from 35 to 15 as shown in table 6.

Dynamic responses of change in electrical power output in G3, G5 and G9 are shown in figure 8. It is observed here that the dynamic response of the change in electrical power deteriorates due to change in PSS gain i.e. PSS gain of optimal generators are very sensitive.

In order to observe the effect of PSS gain on speed deviation and terminal voltage the dynamic response of the system with and without PSS were obtained for speed deviation and change in terminal voltage as shown in figure no $9 \& 10$ respectively. It also shows that PSS tuning of three optimal locations of generators, is required for getting best system response.

Table 6 PSS Parameters

\begin{tabular}{|c|c|c|c|}
\hline Machine No. & Kstab & T1=T3 & T2=T4 \\
\hline 1 & 35 & 0.1 & 0.05 \\
\hline 2 & 35 & 0.1 & 0.05 \\
\hline 3 & 15 & 0.1 & 0.05 \\
\hline 4 & 35 & 0.1 & 0.05 \\
\hline 5 & 15 & 0.1 & 0.05 \\
\hline 6 & 35 & 0.1 & 0.05 \\
\hline 7 & 35 & 0.1 & 0.05 \\
\hline 8 & 35 & 0.1 & 0.05 \\
\hline 9 & 15 & 0.1 & 0.05 \\
\hline 10 & 35 & 0.1 & 0.05 \\
\hline
\end{tabular}

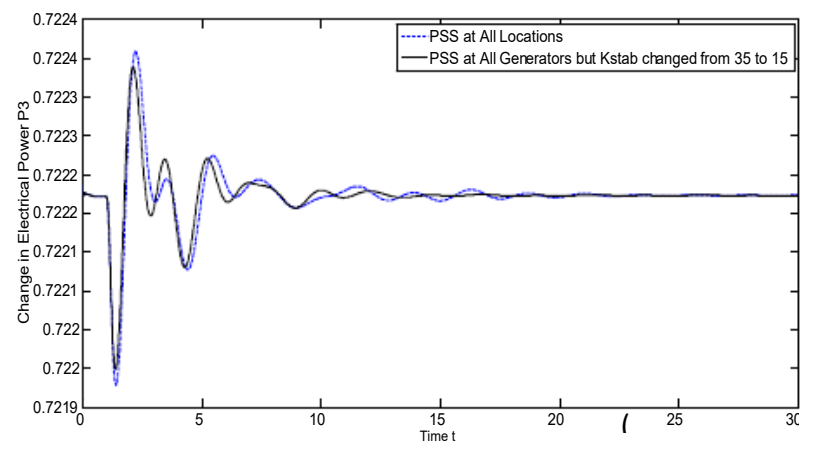



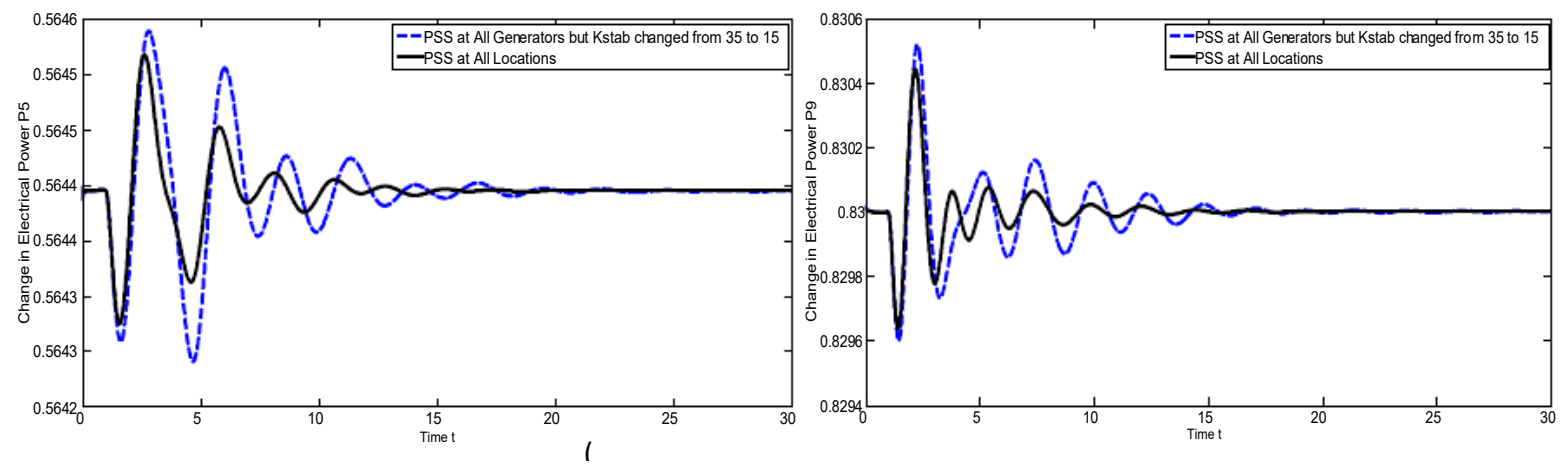

Figure 8 Change in Electrical Power Output of (a) G3 (b) G5 and (c) G9

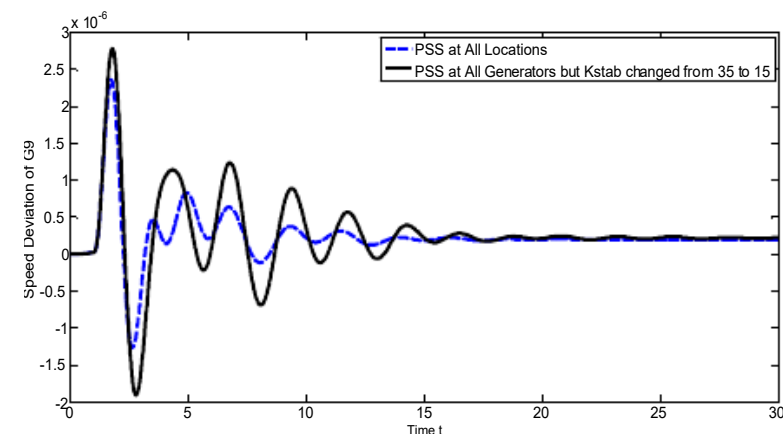

Figure 9 Speed deviation in Generator G9

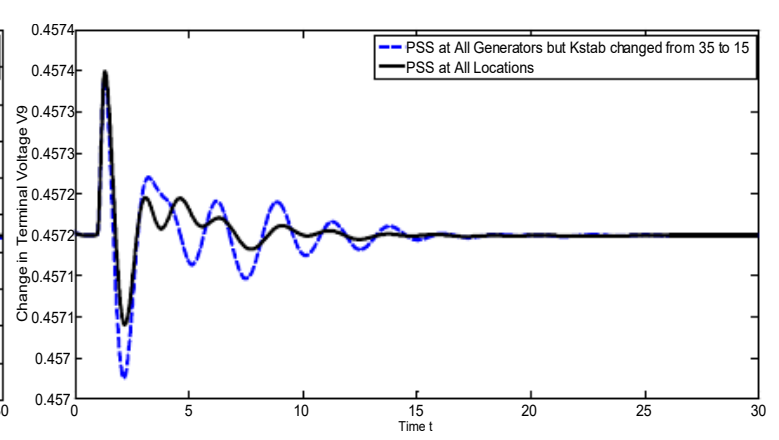

Figure 10 Change in Terminal Voltage of G9

\subsection{Comparative Study of system responses when PSS at three optimal locations and at all generators}

In order to examine the effectiveness of minimum number of PSS at important locations (whose participation factor is high), dynamic response of the system was obtained by installing PSS only at generator 3,5 and 9 .

This section describes some emphasis on the behavior of the system with PSS at all locations and with PSS only at optimum locations. PSS parameters which are considered for simulation study for three optimal locations are shown in Table 7.

Table 7 PSS Parameters

\begin{tabular}{|c|c|c|c|}
\hline Machine No. & Kstab & $\mathbf{T 1}=\mathbf{T 3}$ & $\mathbf{T 2}=\mathbf{T 4}$ \\
\hline 1 & 0 & 0.1 & 0.05 \\
\hline 2 & 0 & 0.1 & 0.05 \\
\hline 3 & 35 & 0.1 & 0.05 \\
\hline 4 & 0 & 0.1 & 0.05 \\
\hline 5 & 35 & 0.1 & 0.05 \\
\hline 6 & 0 & 0.1 & 0.05 \\
\hline 7 & 0 & 0.1 & 0.05 \\
\hline 8 & 0 & 0.1 & 0.05 \\
\hline 9 & 35 & 0.1 & 0.05 \\
\hline 10 & 0 & 0.1 & 0.05 \\
\hline
\end{tabular}



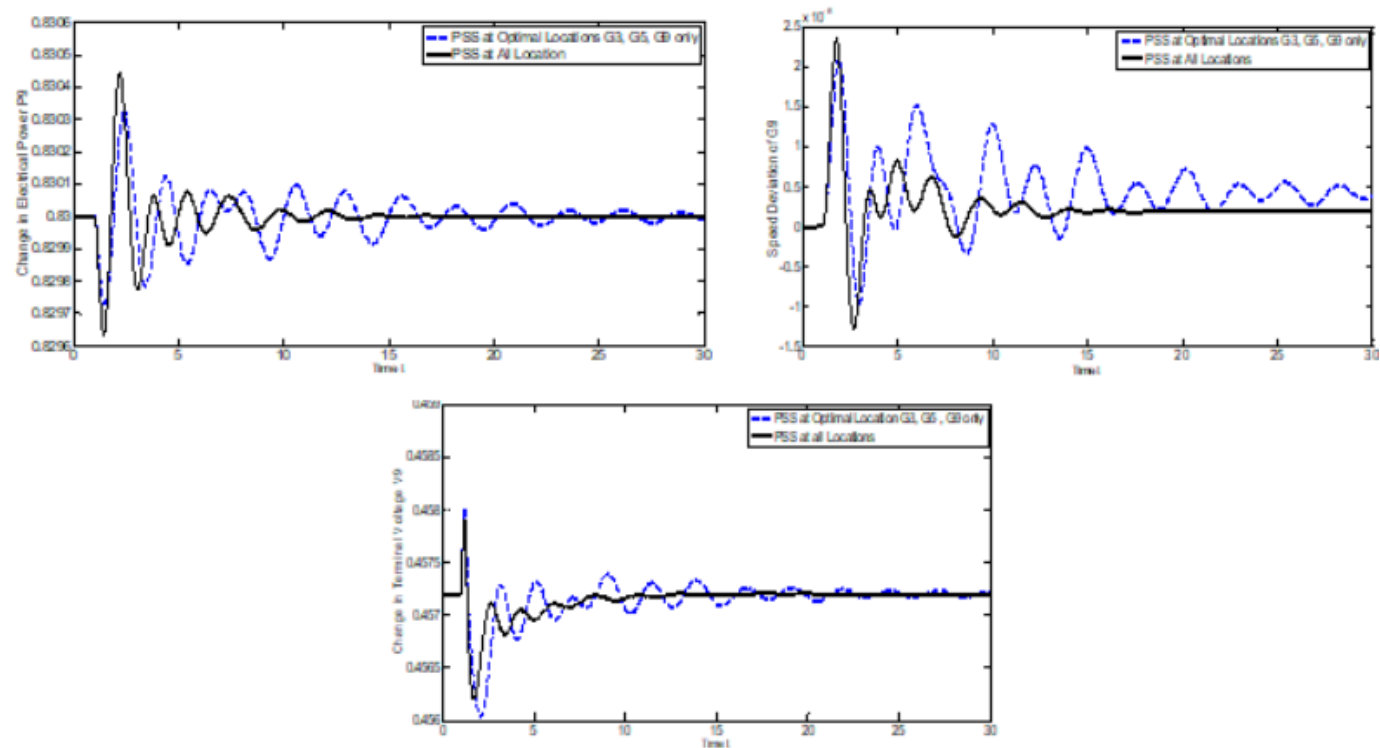

Figure 11 Dynamic response of the system for (a) Electrical Power Output (b) Speed Deviation and (c) Change in Terminal Voltage

Figure 11 shows the dynamic response of the system for (a) Change in Electrical Power, (b) Speed deviation, (c) Change in terminal voltage. For comparative study point of view the dynamic response of the system with PSS installed at all generators are also shown in the figures. Dotted lines are used for response of the system when PSS are installed at only three optimal locations and bold lines are used for showing the dynamic response when PSS are installed at all generators. Examining the responses, it can be concluded that the performance of the system in both cases are almost similar, however responses of the system when 3 PSS are installed at 3 optimal locations, can further be improved by fine tuning of PSS parameters.

\subsection{Study the effect of tuned PSS at only three optimal locations}

In order to study the effectiveness of finely tuned PSS parameters using Particle Swarm Optimization (PSO) technique for optimal locations of generators (G3, G5 and G9), simulation studies were carried out on simulink by considering $1 \%$ step change in mechanical input power at G8 after $1 \mathrm{sec}$. A Matlab Program was developed as per the flow chart (Figure 4) given in section $\mathrm{V}$. The developed computer program was executed on Dell Lattiture core i5 $(2.5 \mathrm{GHz})$ 4 GB RAM system for getting optimal two parameters of each PSS (Kstab \& $\mathrm{T}_{1}$ ), i.e., six parameters are to be tuned for three generators G9, G5 \& G3. In each iteration, the simulink model of the system was executed to obtain six tuned parameters as explained in section $\mathrm{V}$. The optimized PSS parameters obtained by using particle swarm optimization technique are presented in table 4 of section $\mathrm{V}$ and same are considered here for simulation study. For comparison point of view, the dynamic responses for change in electrical power, speed deviation and change in terminal voltage of generator 9 were obtained using optimized PSS parameters of three generators and are plotted on figure 12. Figure 12 shows that, by using optimized PSS, settling time reduces. Also, the peak amplitude of initial disturbance is small as compared to the un-optimized PSS. The damping/speed deviation in the system is improved by using optimizing the PSS parameters. The voltage waveform shows that it is less affected with the application of optimized PSS values, whereas electrical power output is affected more and quite improved by introducing the optimized PSS. 

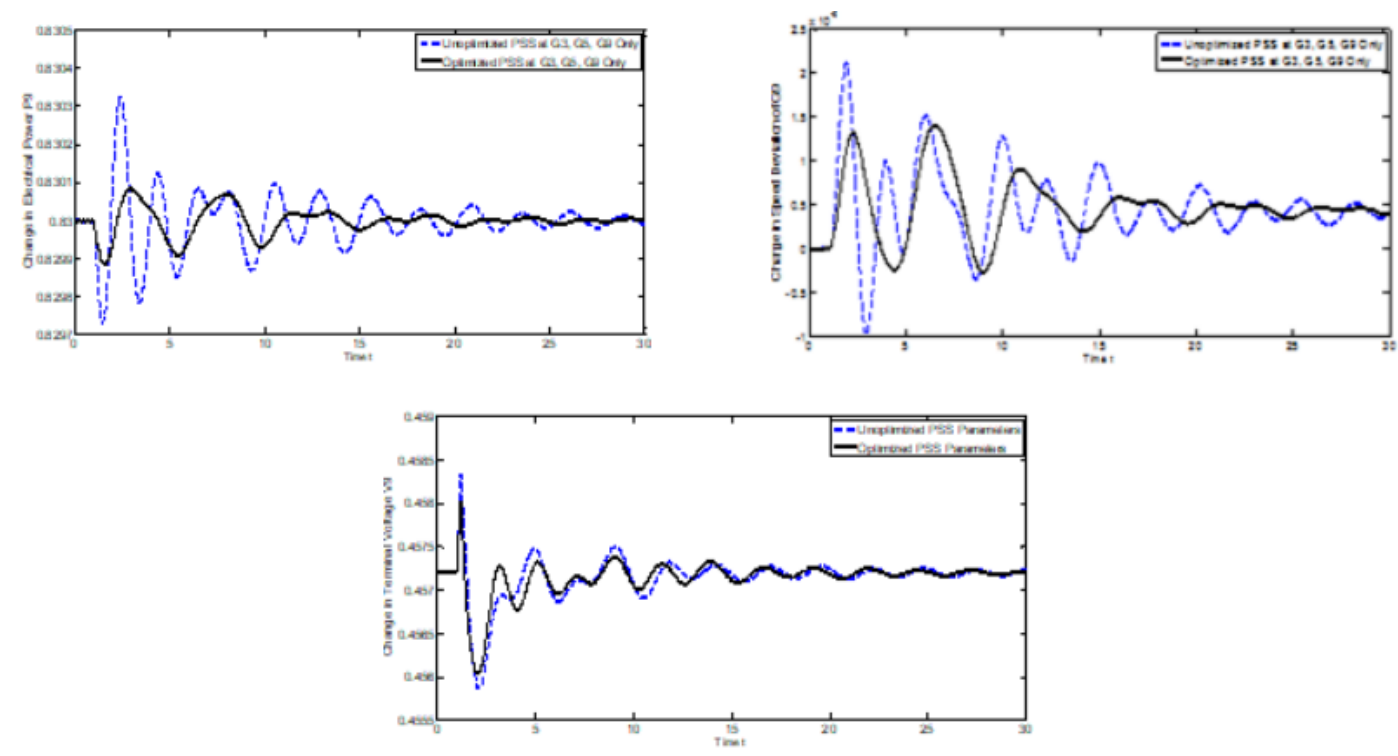

Figure 12 Dynamic Responses of Machine G9 for (a) Change in Electrical Power Output (b) Spqed Deviation and (c) Change in Voltage

\section{CONCLUSION}

This paper describes the Simulink model of IEEE 10 Machines 39 bus New England system and studies have been carried by developing its generator model, Excitation system model and PSS model in Simulink Matlab 2014. After building the complete Simulink model, system analysis was carried out and the PSS parameters are optimized using Particle Swarm Optimization Algorithm. The comparative analysis shows that, with PSS only at three optimal locations gives equally good performance as compared to the PSS at all locations. Also, by optimizing the PSS parameters of generators G9, G5 and G3 using PSO the responses were more stabilized and effective.

\section{REFERENCES}

[1] M. J. Morshed and A. Fekih, A Probabilistic Robust Coordinated Approach to Stabilize Power Oscillations in DFIG-Based Power Systems, IEEE Transactions on Industrial Informatics, 2019.

[2] A. Farah, A. Kahouli, T. Guesmi, and H. H. Abdallah, Dual-input power system stabilizer design via JAYA algorithm, 2018 15th International Multi-Conference on Systems, Signals and Devices, SSD 2018, 744-749.

[3] K. M. Pradeep and V. Mini, Mitigation of inter area oscillations in a two area system using PSS and STATCOM, Proceedings of 2018 IEEE International Conference on Power, Instrumentation, Control and Computing, PICC 2018, 1-5.

[4] C.-H. Lin, C.-J. Wu, J.-Z. Yang, and C.-J. Liao, Parameters identification of reduced governor system model for diesel-engine generator by using hybrid particle swarm optimisation, IET Electric Power Applications, 12(9), 2018, 1265-1271.

[5] P. Kundur, Power system stability and control, McGraw-Hil, Third Edition, 2017.

[6] T. Tarif, A. A. Ladjici, and Y. Chabane, A multi-objective approach to PSS optimal tuning and placement for small-signal stability enhancement, 2017 6th International Conference on Systems and Control, ICSC 2017(2), 601-606.

[7] H. B. Flores, J. C. Cepeda, and C. F. Gallardo, Optimum location and tuning of PSS devices considering multi-machine criteria and a heuristic optimization algorithm, 2017 IEEE PES 
Innovative Smart Grid Technologies Conference - Latin America, ISGT Latin America 2017, $1-6$.

[8] J. L. Rueda, J. C. Cepeda, and I. Erlich, Estimation of location and coordinated tuning of PSS based on mean-variance mapping optimization, in IEEE Power and Energy Society General Meeting, 2012, 1-8.

[9] A. Ghasemi, H. A. Shayanfar, M. S. Naderi, and O. Abedinia, Optimal placement and tuning of robust multimachine PSS via HBMO, International Conference on Artificial Intelligence, vol. 2, in Proceedings of the 2011

[10] G. Rogers, Power System Oscillations. Springer US, 2011.

[11] M. Eslami, H. Shareef, A. Mohamed, and M. Khajehzadeh, Optimal location of PSS using improved PSO with chaotic sequence, InECCE 2011 - International Conference on Electrical, Control and Computer Engineering, 2011 253-258.

[12] D. Mondal and A. Sengupta, "PSO based tuning and optimal allocation of tcsc controllers to mitigate small-signal stability problem," Proceedings of the 2010 Annual IEEE India Conference: Green Energy, Computing and Communication, INDICON 2010, 1-4.

[13] K. Sebaa and M. Boudour, "Optimal locations and tuning of robust power system stabilizer using genetic algorithms," Electric Power Systems Research, 79(2), 406-416.

[14] S. Q. Yuan and D. Z. Fang, Robust PSS parameters design using a trajectory sensitivity approach, IEEE Transactions on Power Systems, 24(2), 1011-1018.

[15] K. A. Folly, Multimachine power system stabilizer design based on a simplified version of genetic algorithms combined with learning, Proceedings of the 13th International Conference on Intelligent Systems Application to Power Systems, 2005, 240-246.

[16] T. Jeevan Kumar, M.L. Kothari, Avdhesh Sharma, Design of Conventional and Fuzzy Logic Power System Stabilizers for a Multi-Machine Power System, National Power Systems Conference, at IIT Madras, 2004 262-267.

[17] P. Bera, D. Das, T. K. Basu, Design of P-I-D Power System Stabilizer for Multimachine, IEEE India Annual Conference (INDICON), 2004, 446-450.

[18] M. A. Abido, Optimal power flow using particle swarm optimization, International Journal of Electrical Power \& Energy Systems 2002, 24(7), 563-571.

[19] M. A. Abido, Optimal design of Power System Stabilizers Using Particle Swarm Optimization, IEEE Power Engineering Review, 22(7), 406-413.

[20] "Power System Toolbox Version 2.0", Cherry Tree Scientific Software - PR\#5 Colbome Ontario KOK ISO Canada, 1999.

[21] Dr. S. Sridhar, S. Sabareesanand Dr. R. Kannan, Particle Swarm Optimization Approach for Flow Shop Scheduling Problem - a Case Study, International Journal of Mechanical Engineering and Technology, 9(11), 2018, pp. 72-80.

[22] G.A. Yuryev, E.K. Verkhovskaya and N.E. Yuryeva, Particle Swarm Optimization for Multidimensional Clustering of Natural Language Data, International Journal of Civil Engineering and Technology, 9(11), 2018, pp. 139-149.

[23] P. Sobha Rani and Dr. A. Lakshmi Devi, Performance Improvement of Distribution System with Multi Distributed Generation Using Particle Swarm Optimization, International Journal of Electrical Engineering and Technology (IJEET), Volume 5, Issue 2, February (2014), pp. 44-50

[24] Anuradha L. Borkar, Self-Accelerated Smart Particle Swarm Optimization for Non Linear Programming Problems, International Journal of Electronics and Communication Engineering \& Technology (IJECET), Volume 4, Issue 5, September - October, 2013, pp. 218-224 
[25] Harinder Pal Singh, Yadwinder Singh Brar and D. P. Kothari, Solution of Optimal Power Flow Based on Combined Active and Reactive Cost using Particle Swarm Optimization, International Journal of Electrical Engineering and Technology, 10(2), 2019, pp. 98-107.

[26] Nayan Ranjan Samal and Samita Padhi, Topology and Parameter Selection of Particle Swarm Optimization- A heuristics Study: International Journal of Electrical Engineering \& Technology, 9(3), 2018, pp. 50-60

[27] M. Venkatesh and B. Jagannath Yadav, A Novel Approach to Optimal Design of PI Controller of Doubly Fed Induction Generator using Particle Swarm Optimization. International Journal of Electrical Engineering \& Technology, 8(1), 2017, pp. 09-16.

\section{AUTHOR DETAILS}

AVDHESH SHARMA received the BSc. Engg. (Electrical) from D.E.I. Engg. College, Dayalbagh, Agra, in 1983, M.Sc.Engg. (Instrumentation \& Control) from AMU, Aligarh in 1987, M.Tech.(CSDP) from IIT, Kharagpur in 1992 and Ph.D. (Electrical Engineering) from Indian Institute of Technology, New Delhi in 2001. He worked as Assistant professor and Associate Professor at M.B. M. Engg. College, Jodhpur (Rajasthan). Presently, he is working as professor in M.B.M. Engg. College Jodhpur (Rajasthan). His research interests include Power System Stabilizers, unit commitment, power Quality, Artificial Neural Network(ANN) and Fuzzy Logic Systems.

RAJESH KUMAR received his B.Tech. and M.E. degrees in Electrical Engineering from RTU, Kota and JNVU Jodhpur respectively. He is currently pursuing his Ph.D. from the MBM Engineering College Jodhpur Rajasthan. His research interests include distribution and transmission network in power systems, optimization, system theory, smart grid and wide area monitoring and control system. 